\title{
Cyclic-Temporal Competitive Advantages of the National Economy and Entrepreneurship Development
}

\author{
Vitaliy Vasilievich Biryukov ${ }^{1}$ \\ Elena Vasilievna Romanenko 1 \\ Saida Mindualievna Khairova ${ }^{1}$ \\ Bari Galimovich Khairov 1,2
}

1 Faculty of Economics and Management, The Siberian Automobile and Highway Academy (SibADI), Omsk, Russian Federation 2 Financial University under the Government of the Russian Federation (Financial University), Moscow, Russian Federation

\section{Doi:10.5901/mjss.2015.v6n4s4p64}

\section{Abstract}

The article deals with the pressing issues of the growing significance of time as a fundamental factor in the economy development and the competitive behavior of firms. It proposes a conceptual approach to the time phenomenon analysis, in which, based on a synergetic paradigm, the temporal dimension of economy is viewed as a special projection (context), which allows studying its temporal characteristics, as well as functions of time acting as a system-forming phenomenon. The paper, in line with the developed approach, reveals the role of time as a unique instrument to measure the growth of productivity of innovative activities and to regulate allocation of resources in the economy. It is concluded that the level of gross domestic product (GDP) production per time unit reflects the performance of human resources and describes the value of time as a system parameter. At the same time the cost of production becomes a monetary form of manifesting the consumption of aggregate (macroeconomic) time, and the market price becomes the monetary value of the amount of macro-economic time, which a buyer is ready to spend on purchasing a product based on an available income. It is proved that the main source of income exceeding the normal level is innovation, which helps increase the productivity, save time and create Schumpeterian and Kirznerian rents. It shows the role of time as a coordinator of the rhythms of changes in industrial and technological, organizational and institutional, cultural and value connections. It considers the issues of changes in the temporal paradigm of development of entrepreneurial firms' competitive advantages, as well as of strategic management with a focus on time as a competitive factor.

Keywords: national economy, entrepreneurship, time factor, temporal competitive advantages, economic effectiveness.

\section{Introduction}

A sharp acceleration of institutional and technological processes resulting in fast-moving changes is the fundamental feature of our time. Due to its exceptional significance, the factor of time (speed) has become a fundamental dominating factor in the modern economy, in shaping competitive advantages of entrepreneurial structures and differentiation of their income.

Development of national economy acts as a process of changes that take place in time and space. The dynamic nature of economic life in modern conditions significantly changes, time-wise, the sources, factors and mechanisms that generate and realize competitive advantages of national economies. Competitive advantages defined by the timeframe of the opportunities corridor act as cycle-temporal (time) benefits, the new contours of which originate in the structures of the present.

Today, time is turning into a special factor that determines success or failure in competition. However, recording of the time factor is one of the most difficult aspects of economic activity organization.

Creation of an adequate theory of innovative development of a national economy and its competitive advantages involves elimination of gaps related to the underestimation of the time phenomenon, developed within the traditional paradigm, and a revision of misconceptions. 


\section{Literature Review}

Searching for a new economic paradigm inevitably leads to the necessity to rethink the concept of time. It was Alfred Marshall who noticed that "the time factor is at the heart of the main difficulties while dealing with almost any economic problem" (Marshall, 1993). According to Alvin Toffler, "revision of the concept of time is an integral part of a grand revolution occurring in modern science and culture" (Toffler, 1999).

Alternation of the scientific paradigm made the need to rethink the phenomenon of time and its role in social studies more pressing. In this regard as early as in 1937, P.A. Sorokin and R.K. Merton identified social time, which differs from the natural (astronomical) time, has a social meaning and is socially structured (Sorokin and Merton, 1937).

In the classical political economics, following the tradition established by Adam Smith, David Ricardo and Carl Marx, in many ways the time phenomenon acted as its key feature, but at the same time special attention was paid to its special role of a special tool used to measure cost of production and control market prices, while its asymmetry and polyactivity of its structure remained underestimated. The neoclassical paradigm established as a result of the marginal revolution had resulted in the domination of studies based on stationary models of economic development, wherein the time phenomenon was either not taken into account at all, or to a rather limited extend. In the second half of the twentieth century, as a part of the framework of a consumer welfare theory, Gary S. Becker, Staffan B. Linder and other scientists on the basis of recording the time factor as one of the valuable resources - developed a more universal approach, according to which a person does not focus on increasing his/her cash income, she/he takes into account the usefulness of time and seeks to optimally distribute his/her time in general (Becker, 1964; Linder, 1970).

The limited nature of the neoclassical paradigm contributed to the development of institutional and evolutionary direction that expanded the subject field of research by taking into account the limited knowledge and uncertainty of the future and focused on studying how the heredity, variation and selection processes happen in economy in time. And the role of institutions is usually associated with the need to minimize transaction costs (Williamson, 1996).

The evolutionary approach was used as the basis for the analysis of cyclical mechanisms of technological and institutional changes' interaction as part of the long waves' theory. Works by Gerhard Mensch, who divided innovations into base and improving ones (Mensch, 1985), Giovanni Dosi, who studied the process of formation of technological trajectories (Dosi, 1982) and Carlota Perez, who introduced the concept of the technical and economic paradigm (Perez, 1983) were very important for stimulating discussion on those issues.

To explain a firm development on the basis of innovations, Richard R. Nelson and Sydney G. Winter suggested that it should be regarded as a carrier of various types of routines (Nelson and Winter, 1982). Currently, the research programs that underestimate the significance of business environment high volatility are subjected to critical analysis: the theory of competitive strategies, resource concept (Porter, 1980; Barney, 1991), etc., while more realistic dynamic approaches are being actively developed: theory of a firm based on knowledge, the concept of dynamic capabilities, the ecosystem approach (Kogut and Zander, 1992; Helfat et al., 2007; Chessell, 2008), etc. However in general the prevailing theoretical and methodological tools related to studying the processes of competitive behavior of economic structures and systems taking into account the multidimensionality of the time phenomenon remain mostly undeveloped.

\section{Method}

Economic processes always happen in real time. However, the cognitive structures developed in the framework of the neoclassical paradigm that got established in the XX century, do not allow to satisfactorily correlate behavior models of various economic and entrepreneurship entities with concrete historical conditions of their activities. Describing of the micro- and macro-economic processes in real time becomes more and more difficult.

To develop a satisfactory research program one should take into account changes that occur in the modern scientific perception due to switching from a traditional scientific paradigm based on using static, strictly deterministic, linear causal and reductionist methods to a new paradigm oriented towards the application of dynamic, multidimensional, cycle-cause, holistic and co-evolutionary approaches. In describing the conceptual revolution, llya Prigogine and Isabelle Stengers point out that science is rediscovering time, and radical changes in the world's vision towards multiplicity, temporality and complexity help discover new aspects of time (Prigogine and Stengers, 1986). As part of the synergetic paradigm it becomes possible to consider the time not just as one of the fundamental parameters of a national economy and entrepreneurial firms' development, but as its system-forming reality, end-to-end principle of organization and transformation of economic systems, which allows not only to study their individual components, but also to connect different parts of a complex and dynamic picture of the world on the basis of more universal cognitive structures. The theory of formation of the innovative economy and of the mechanisms of entrepreneurial firms' competitive advantages 
needs to be radically linked with the time phenomenon. It means one will have to abandon various representations and ideological statements that relate to the underestimation of the phenomenon of time, and consider it some makeweight to economic concepts and a simple counting unit of measurement, and mixing of the temporal aspects of the analysis of macro- and micro-processes, etc.

\section{Results}

The time dimension of the national economy should be considered as its special projection (context), which allows us to study temporal characteristics of economic processes and the organization of economic activities of entrepreneurial structures. Within the framework of a synergy paradigm time ceases to be just one of the limited resources and some external unit of account; in a poly-temporal economy it becomes its system-forming factor and has a complex structure.

Time as a system-forming phenomenon has a special function, its acts as a tool to measure costs and results of innovations, it controls supply and demand, as well as the allocation of resources in national economy, it coordinates the rate of changes in the production and technological, organizational and institutional, cultural and value systems.

The trigger of system changes in the national economy is a critical mass of subjects with a new level of mental and creative abilities that ensure adaptation to rapidly changing business environment. To develop a successful strategy, it is important to take into account the formation of a new temporal paradigm of competitive behavior of firms; this involves a shift from a reactive to a proactive behavior model that enables you 'to compete for the future' on the basis of advancing creation and development of unique resources and competencies.

\section{Discussion}

\subsection{Time as a unique tool for measuring the growth of innovative activities' productivity and controlling the resources allocation in economy}

The trajectory of the economy's innovative development is always formed as a result of the activities of its subjects, generating and using business energy. Under the current structural conditions the output of gross domestic product (GDP) Y will depend on the economic work performed by the subjects, the value of which is determined by their labor productivity $\mathrm{A}$ and use of the macroeconomic (total) time $\mathrm{T}$, i.e. $\mathrm{Y}=\mathrm{A} \times \mathrm{T}$. Unlike all other types of resources, the resulting macro-aggregate of the human resources performance $A=Y / T$ plays a special role, it characterizes the value of time and becomes a system regulator of the economy, the basis for setting a monetary estimate of production costs and the market value of the products (Biryukov and Biryukova, 2009). The interaction of aggregate supply and aggregate demand, and the formation of macro-balance in the national economy are based on the implementation of the dual functions performed by the aggregate time.

First, from the supply point of view the cost of production (w) expresses the value of the aggregate (macroeconomic) time (tw), consumed during all stages of its production, starting from extraction of raw materials, i.e., tw $=w / A$. Secondly, in terms of consumption, the income of each buyer $(S)$ characterizes the macro-economic resources of time (Ts), which the buyer can use, i.e. Ts = S/A, and the market price (s) indicates the amount of time resources (ts), which is used for the purchase of the product, i.e. ts = s/A (Biryukov, 2010).

So time is a measure of the cost and value (usefulness) of goods. As Marx noted, "Society pays for products by using a part of its working time for their production, therefore, it buys them with a certain amount of working time, which it... could have" (Marx and Engels, 1961). Competition, fluctuations of market prices, supply and demand lead to a redistribution of economic resources, which maximizes the performance of the national economy, based on the prevailing social preferences regarding the directions and forms of using the total time fund. In this regard, as emphasized by F. Thomas Juster and Frank Stafford, "the fundamental scarce resource in the economy is availability of human time, and allocation of time to various activities will ultimately determine relative prices of goods and services" (Juster and Stafford, 1991).

Economic development takes place through innovations that are generated and implemented by various entities. Today, more and more researchers consider human resources as the main source of value, economic growth and sustainable competitive advantage (Prahalad and Hamel, 1990; Barney, 1991; Pfeffer, 1994), and the ideas, innovation and creativity are recognized as a special economic resource, since ultimately creativity is what improves productivity (Florida, 2002).

Innovations are the driving force behind economic development and the main source of profits in excess of the normal level. Radical and incremental innovations help increase productivity, save time and create surplus (extra) time, 
Schumpeterian and Kirznerian rents. The traditional economic theory cannot explain the paradox of profit absence in the balance. As Schumpeter observed, "Surplus values may be impossible in perfect equilibrium but can be ever present because that equilibrium is never allowed to establish itself. They may always tend to vanish and yet be always there because they are incessantly recreated" (Schumpeter, 1995).

Using the synergetic paradigm of time allows you to create a system-holistic understanding of the mechanism of economic gain based on innovations. From the standpoint of the national economy the national product created in the current period expresses the amount of time used by business entities and arises from the combination of simultaneous consumption of business energy of the workers, producing benefits for current consumption, and investment benefits. To create new instruments of labor to replace retiring ones, it is necessary to spend part of the total time resources the society has in this time period, thereby accumulating the annual depreciation fund, which reflects the corresponding part of the gross added value newly produced in the given year. Thus, the time t of each economic entity, with an increase in its activities' productivity, is divided by not only the required (tc) and surplus ( $\Delta \mathrm{t})$ time, but also by the time spent on the reproduction of the consumed fixed capital (ti), i.e. $t=t i+t c+\Delta t$, while $\Delta t=t \Delta A / A$, where $\Delta \mathrm{A} / \mathrm{A}$ is the share of labor productivity increase in the total value (Biryukov and Romanenko, 2011).

The level of labor productivity $A=Y / T$, emerging in the national economy, determines the value of the unit of time and competitive positions of the country, and its increase in the long-term horizon based on the generation of innovations and their transfer provides for the occurrence of a time surplus and becomes a strategic benchmark for technical and economic systems' development. Furthermore, the different directions for saving resources - fuel, electricity, metal, materials, etc. - eventually serve to save time resources of the society. The growth of a firm performance leads to an increase in the created added value $(\Delta \mathrm{S})$, which characterizes its contribution to the total time savings $(\Delta \mathrm{ts})$, where $\Delta \mathrm{ts}=$ $\Delta \mathrm{S} / \mathrm{A}$.

\subsection{The system of time coordinates as the coordinator of the rhythms of changes in production and technological,} organizational and institutional, cultural and value relations

The system of time coordinates helps to correctly interpret the evolution of economy, taking into account the contradictory of the interaction of its trajectory dependence on the developments in the past (path dependence) and in the future in the context of changes in three key types of structure-forming links: cultural values, organizational and institutional, and technical-industrial. These ties have a mutual determination, but are not rigidly interdependent and perform different roles in the implementation of innovative changes. The trigger that launches innovation processes is the accumulation of experience and knowledge related to the discovery of new opportunities for better utilization of time resources through organizational and technological innovations, and an update of the dominant cultural-value concepts taking into account expected changes in the environment.

The economic behavior expresses a contradictory interrelation between structural conditions and mental-creative abilities of people, describing the result based on the use of cultural-value orientations. Normalizing human interaction, institutional system performs an instrumental function; it facilitates the increase in productivity and time saving by getting system-synergy effect from the division of labor, cooperation, network structures and innovations. This matrix is the result of harmonizing partially overlapping, but to some extent conflicting private and public interests, depending on the mutual benefits received; it determines the overall level of complementarily and dysfunctionality of the institutional system. The general corridor (vector) of economic and business development in time is set by the knowledge base and platform technologies, institutional matrix, cultural and value orientation.

The established level of economic development forms a bunch of technological opportunities for changing the economic growth trajectory, and the cultural-value and institutional systems determine the spectrum of really possible changes in economy in the time. In accordance with the degree of time association of cultural-value, institutionaltechnological structures, more or less stable economic and technological formations are created which are displayed as some integrities. This is the basis for various ways of organizing time and economic growth model. Depending on the duration of the reproductive structures' evolution eras, stages and periods of economic development, techno-economic patterns and economic cycles change. The process of substituting traditional technical and economic structures with new ones is cycle-cause and non-uniform in time. Models reflecting the S-shape of the economic dynamics are quite successfully used in the practice of forecasting.

The increase in the time value caused by the acceleration of social and economic processes is happening today under conditions of significant differences in the dynamics' rates of economic systems. This asymmetry brings forth the key issue of the modern economy: time dispersion both within individual countries and in the international arena, between countries and the technical and economic formations, which causes extensive time intervals ("time gaps"). Changing the 
technical-economic paradigm as part of the current technological revolution offers the implementation of fundamental changes in the business and value baselines, investment behavior, organizational models that maximize efficiency, and institutions (Perez, 2002).

The research shows that during global technological breakthroughs on the back of the new technological order growth there is a 'window of opportunity' to replace the composition of leading companies, countries and regions. It will consist of those who are able to quickly move to the growth trajectory of the new technological pattern, and for those lagging behind such transition will be getting more expensive every year. In industrially developed countries there are specific factors that shape the inertness of technological leaders: the need to benefit from past investment in physical, human and intellectual capital, earlier signed contracts, the risks of using alternative technologies, etc. There the leaders develop specific barriers restraining the speed of radical innovations' spreading as there is excess capacity in the obsolete technological structures. However, the success of applying advanced technologies for the breakthrough into technology leaders' group depends on many conditions, which form entry barriers impeding effective adaptation of borrowed innovations. With an adequate scientific and educational potential to copy the scientific and technological achievements of the advanced countries and to train the personnel in the best design and engineering practices, the BRIC countries are able to take the lead by changing technological patterns and promptly "ride" a new long wave of economic growth (Glaziev, 2015).

\subsection{Changing the temporal paradigm of development of entrepreneurial firms' competitive advantages}

The formation of mechanisms of competitive advantage development in time is mainly determined by the stage of the product life cycle. As part of the life cycle of a product (technology), improvements - from the origination to maturity - may be presented in the form of an S-shaped curve. During the origination of a product a Schumpeterian entrepreneur acts as a driving force, who masters radical innovations, and at later stages a Kirznerian entrepreneur becomes crucial as he restores balance in the economy. Initially, various models of the product compete; as the dominating model emerges the competition takes place within different variants of the same model in the emerging mass market. At that, breakthrough innovations are replaced by incremental or gradual ones, acquiring imitation character.

The current state of competition is defined as hyper-competition, specifying the following of its features: dynamic changes; multi-dimensionality of goals and interests pursued by competitors, and increased aggressiveness of the fight (D'Aveni, 1994). Shift to the hyper competition is linked to the occurrence of a new temporal paradigm of businesses' behavior, and high level of the change dynamics eliminates the possibility of maintaining superiority over a competitor for a long time without creating new advantages. Hyper-competition changes the mechanism of competition, there is a competition for market leadership, it focuses on the constant generation of innovations that allow creating competitive advantages faster than competitors, attack suddenly and with devastating effect. Hyper-competition undermines the role of barriers that restrict competition: technological, trading, patent, license, etc. The ability to find weaknesses of competitors, break barriers and to promptly abandon obsolete advantages and create new ones becomes extremely important to a business structure.

In modern conditions, "time becomes a strategic success factor, since, first of all when you were late to penetrate the market the time of your presence there is not enough to cover the high fixed costs; secondly, a new standard can be formed that will predetermine further development of the market ... it's not that big competitors devour small ones, it's that fast competitors swallow up less efficient ones" (Weiber, 2003). Under the new conditions the significance of the economy of scale reduces, as well as of capital intensity and other factors that determine the advantages of large companies. Small-sized firms, that can be competitively flexible, can often compensate for their weaknesses by developing cooperative relations and incorporating into business networks.

Today, it is not enough to have unique resources and competencies to create sustainable competitive advantages of the company; it is necessary to possess required dynamic capabilities and relevant procedures for the timely adaptation of resources and competencies to changing environment. Operational management toolkit allows to apply not proactive, but reactive approach and in the best case to obtain temporary competitive advantage and the corresponding types of rents (Ploskonosova, and Romanenko, 2012). It is necessary to have a strategy of the rational combination in time of the company's orientations: searching for new things (exploration) and using the existing ones (exploitation), effectiveness and efficiency. The effectiveness characterizes the firm's ability to create innovation and exercise proactive management in order to meet the changing needs of the market, and efficiency - its ability to turn into routine the processes and procedures that ensure the improvement of existing products, technologies and business management practices.

The experience of developed countries proves that ventures business is the locomotive which helps create and 
implement large-scale innovative processes. Furthermore, the priorities of socio-economic and scientific-technical policies of the state change radically; and such policies are focused on the development of the national innovative system and establishment of effective networks between research centers and universities, private firms and organizations involved in the creation of new knowledge. Furthermore, particularly important is the formation of an innovative infrastructure, creation of economic incentives and a favorable business environment that facilitates free flow of knowledge, implementation of innovative and communication technologies and entrepreneurship development (Khairov and Khairova, 2007). The choice of strategic priorities for the changes implementation by business structures requires a deeper understanding of these processes, taking into account current starting conditions, the space of temporal opportunities, threats and challenges of non-industrial stage of development.

\subsection{Strategic management of a business structure, including time orientation as a competitive factor}

To be able to develop successful temporal strategies for firms' development in the innovative competition, it is important to abandon a simplistic understanding related to the absolutization of differences between imitation and innovation. Underestimating the importance of the active imitation of innovations by business entities is based on Schumpeter's interpretation of business activities as activities of a leader-innovator, who is constantly threatened by "swarms of imitators", eager to release a similar product (Schumpeter, 1995). However, back in the 1970s, while developing an understanding of entrepreneurship, Kirzner pointed out the special role of such its form that provides for mass distribution of innovations through the creation of profitable businesses (Kirzner, 2010).

While analyzing competitive strategies it is important to consider the variety of different variants of simulation as a space, which characterizes the transition from a pure imitation to pure innovation through creative imitation. Under conditions of the innovative competition the time period during which the chasing firms mimic successful practices of the leader company, has considerably reduced. Reduction of the imitation lag and the variety of changes' managing methods used by companies resulted, as noted by Mikael Samuelsson and Per Davidsson, in the obliteration of the distinction between innovative and imitation strategies in enterprises; simulation has become an integral part of the innovation process; in practice, exclusively innovative company, or a company-simulator in its 'pure' form, are rare (Samuelsson and Davidsson, 2008).

The correct choice of time period to implement the incremental innovations plays a key role in the formation and implementation of nonlinear changing competitive advantages of business entities. It is important to take into account the stage of the life cycle of the basic innovation, the nature of the imitation and specifics of the market situation development in the territory under consideration. Both a too early start and a delay may prevent the subject from succeeding in the innovative competition.

Studies of successful strategies of the economies that are catching up, and which allowed taking advantage of a late start, to break out from the "underdevelopment traps" and significantly reduce the technology gap, suggest gradual process, which is accompanied by a change in the strategic goals, forms and management tools when approaching the level of leading companies. Furthermore, dynamic development of business structures is carried out as a result of the transfer of foreign technologies, formation of the growing process of knowledge generation and application of enhancing innovation, better adapted to the changing business environment (Bolton, 1993; Kim, 1997).

Different market segments vary in their sensitivity to the time factor. Focus on time-saving as a priority direction for a competitive strategy implies the formation of dynamic capabilities that aim to ensure the benefits due to the rational use of the aggregate time of customers, firm employees and suppliers of resources, the activities of which at all stages of production determine the production costs. Therefore, the strategy with a focus on time-saving as the most important target indicators of competitive behavior should not be carried out at the expense of other parameters (quality characteristics of the product, production costs, etc.). Using time as a competitive factor should provide greater value creation and bring additional value to the consumers, which they are willing to pay for with the increased price.

The fundamental difference between the companies that practice traditional forms of competition and competition based on the time factor is linked to the use of different measurement systems. The management oriented on the advanced development of competitive advantages envisages the use of quantitative assessment of the temporal aspects of all key processes, including the time spent during the individual stages of production cycle, designing of new products and technologies, adaptation of business processes, organizational culture, management and marketing methods, and their comparison with standard parameters. This also takes into account another group of indicators characterizing production costs, financial performance, capacity utilization, etc. However, those indicators are controlled on the basis of their importance in the context of the impact the time factor has upon them and the benefits, costs and risks arising therewith. 
The transition to a strategy that is focused on time as a key factor of competition implies radical changes in organizational culture and overcoming of cultural barriers that prevent the formation of dynamic abilities and competences adequate for a changing business environment through the creation of an atmosphere of trust, openness, cooperation, willingness to take risks, encouraging search for innovations and proactive solutions, etc. Apart from overcoming barriers that are purely cultural and related to the revaluation of outdated values, changes in thinking and behavior, it is important to form a broad approach that focuses on creating conditions to generate and develop knowledge of employees, realize the potential and engage the staff in innovative activities to the maximum through a system of continuous learning, as well as various methods and instruments.

\section{Conclusion}

A significant increase in the importance of time in the modern conditions as a fundamental factor of economic life causes an increase in its role as the system-forming phenomenon, which performs specific functions: it acts as a tool to measure economic processes, control labor division and allocation of resources in the national economy, coordinates the process of institutionalization of the economic life, interaction between production and technological and socio-economical rhythms. Due to the unique properties of human resources and their priorities in economic development that arise out of them, the macro-aggregate of labor productivity - unlike all other types of resources - plays a special role of an integral parameter that characterizes the current value of time of an average worker and is a system regulator of the economy. Formation of its positive trend within a long time period becomes a strategic goal and a fundamental criterion for choosing the forms and methods of innovative changes in technical and economic system and the development trajectory of competitive advantages of national economies.

Today in the innovation competition, the paradigm of the temporal behavior of the firm's changes due to the formation of a non-linear time associated with the spread of non-linear conditions and processes of competitive advantages development in the economy. The structure of such regime of time is more complex and multidimensional, and its most important characteristics are the mobility, uncertainty, unexpectedness, irregularity and chaotic nature. Developing a successful strategy envisages the formation of a temporal dynamic abilities and the use of temporal measurement systems that allow to gain benefit by taking into account the dynamics of non-linear time and rational use of aggregate time of all subjects influencing the value creation and goods production that the buyer is willing to pay for with the price that gives economic rent.

The use of a synergy approach to the analysis of the time phenomenon allows one to expand the subject field of research and satisfactorily deal with many current issues related to identifying the methods to develop comparative advantages of different levels of economic structures in the innovative competition. The temporal approach proposed in the paper allows you to define promising directions and strategic priorities, which are advisable to implement to improve the efficiency and competitiveness of business firms on the basis of the inter-related in time leading innovative changes in the resources and competences, which are adequate for the changes occurring in the environment.

The paper has been prepared with the support by the Project as part of the state order of the Ministry of Education and Science of the Russian Federation for 2015 (basic research).

\section{References}

Barney, J. (1991). Firm Resources and Sustained Competitive Advantage. Journal of Management, Vol. 17, 1, (pp. 99-120).

Becker, G.S. (1964). Human Capital: A Theoretical and Empirical Analysis, with Special Reference to Education. - New York: NBER.

Biryukov, V.V. (2000). Time as a factor of economic development in market conditions: monograph. - St. Petersburg: Publishing house of the Saint-Petersburg state University of Economics and Finance.

Biryukov, V.V., \& Biryukova, V.V. (2009). Entrepreneurship and the innovation process in industry: monograph. - Omsk: Publishing house of the Siberian Automobile and Highway Academy.

Biryukov, V.V., \& Romanenko, E.V. (2011). The mechanisms of the formation temporal competitive advantages of economy and development of small business. Vestnik OmGU. Series of economic, 4, (pp. 5-12).

Bolton, M. (1993). Imitation versus Innovation: lessons to be learned from the Japanese. Organizational Dynamics, Vol.21, Issue 3. (pp. 30-45)

Chessell, M. (2008). Innovation Ecosystems: an IBM Academy of technology study. IBM, May.

D'Aveni, R. (1994). Hypercompetition: Managing the Dynamics of Strategic Maneuvering. - New York: Free Press.

Dosi, G. (1982). Technological Paradigms and Technological trajectories. A Suggested Interpretation of the Determinants and Directions of Technical Change. Research Policy. Vol. 11, Issue 3, (pp. 147-162)

Florida, R. (2002).The Rise of the Creative Class: And How It's Transforming Work, Leisure Community and Everyday Life. - New York: 
Basic Books.

Glaziev S.Y. (2015). O vneshnikh i vnutrennikh ugrozakh ekonomicheskoy bezopasnosti Rossii v usloviyakh amerikanskoy agressii [On external and internal threats to the economic security of Russia in the conditions of the American aggression]. Management and Business Administration, 1, 4-21 [in Russian].

Helfat, C., Finkelstein, S., Mitchell W., Peteraf M., Singh H., Teece D., Winter S. (2007). Dynamic Capabilities and Strategic Management: Understanding Strategic Change in Organization. - Malden, MA: Blackwell

Juster, T., \& Stafford, F. (1991). The Allocation of Time: Empirical Findings, Behavioral Models, and Problems of Measurement. Journal of Economic Literature, June 1991. (pp. 471-522.)

Khairov, B.G., \& Khairova, S.M. (2007). Becoming an affiliate is a parity relationship between the state and entrepreneurship. Siberian Trade and Economic Journal, 6, (pp. 144-147).

Kim, L. (1997). Imitation to Innovation. The Dynamics of Korea's Technological Learning. - Cambridge, MA: Harvard Business School Press.

Kirzner, I. (2010). Competition and entrepreneurship. - Chelyabinsk: The Society. [in Russian].

Kogut, B., \& Zander, U. (1992). Knowledge of the firm, combinative capabilities, and the replication of technology. Organization Science, 3, (pp. 383-397).

Linder, S. (1970). The Harried Leisure Class. - New York: Columbia Univ. Press.

Marks, C., \& Engels, F. (1961). Collected works. (p. 204). Vol. 25. Part. 1. (Vols. 1-50). - Moscow: Political literature. [in Russian].

Marshall, A. (1993). Principles of Political Economy. Vol.1. (Vols. 1-3). (p. 47). - Moscow: Progress. [in Russian].

Mensch, G. (1985). On Theory Integration: Towards Economics of Scope. Long Waves, Depression and Innovation. Siena-Florence.

Nelson, R.R., \& Winter, S.G. (1982). An Evolutionary Theory of Economic Change. - Cambridge.

Perez, C. (1983). Structural Change and Assimilation of New Technologies in the Economic and Social System. Collaborative Paper. Futures, Vol. 15, No. 5, (pp. 357-375)

Perez, C. (2002). Technological Revolution and Financial Capital: The Dynamics of bubbles and Golden Ages. - Cheltenham: Elgar.

Pfeffer, J. (1994). Competitive Advantage through People. - Boston, MA.

Ploskonosova, V.P., \& Romanenko, E.V. (2012). The business environment for small business development and entrepreneurial rents. Vestnik SibADI, 1, (pp. 116-120).

Porter, M.E. (1980). Competitive Strategy. - New York: Free Press.

Prahalad, C.K., \& Hamel, G. (1990). The Core Competence of the Corporation. Harvard Business Review, V. 68, 3, 79-91.

Prigogine, I., \& Stengers I., (1986). Order out of chaos. Man's new dialogue with nature. - Moscow: Progress.

Samuelsson, M., \& Davidsson, P. (2008). Does venture opportunity variation matter? Investigating systematic process differences between innovative and imitative new ventures. Small Business Economics, Vol. 33, 2.

Schumpeter, J. (1995). Capitalism, socialism and democracy. (p. 64). - Moscow: Economics. [in Russian].

Sorokin, P.A., \& Merton, R.K. (1937). Social Time: A Methodological and Functional Analysis. American Journal of Sociology, Vol.42, 5, (pp. 615-629).

Toffler, A. (1999). The Third Wave. (p. 20). - Moscow: AST. [in Russian].

Weiber, R. (2003). Empirical laws of the network economy. Problemy teorii i praktiki upravlenija - Problems of Theory and Management Practice, 4, 81-89.

Williamson, O. (1996). The economic institutions of capitalism. Firms, markets, relational Contracting. (p. 28). - St. Petersburg: Lenizdat. [in Russian]. 